\title{
COMENTARIO A LA SENTENCIA DEL TRIBUNAL DE JUSTICIA DE LA UNIÓN EUROPEA DE 19 DE DICIEMBRE DE 2019 (CASO ORIOL JUNQUERAS)
} COMMENTARY TO THE DECISION OF THE COURT OF JUSTICE OF THE EUROPEAN UNION OF 19 DECEMBER 2019 (ORIOL JUNQUERAS CASE)

\author{
Antoni Bayona i Rocamora \\ Parlamento de Cataluña
}

Cómo citar / Nola aipatu: Bayona i Rocamora, A. (2020). Comentario a la Sentencia del Tribunal de Justicia de la Unión Europea de 19 de diciembre de 2019 (caso Oriol Junqueras). Legebiltzarreko Aldizkaria - LEGAL - Revista del Parlamento Vasco, (1): 130-141. https://doi.org/10.47984/legal.2020.005

\section{RESUMEN}

La sentencia del Tribunal de Justicia de la Unión Europea de I9 de diciembre de 2020 (caso Oriol Junqueras) tiene especial relevancia porque determina cuándo y cómo se adquiere la condición de miembro del Parlamento Europeo y se goza, asimismo, de la inmunidad parlamentaria europea. Hasta la sentencia no existía una posición clara al respecto, y el tribunal europeo la resuelve primando el ejercicio del derecho de sufragio por encima de otras condiciones eventualmente establecidas por el derecho de los Estados miembros. La sentencia del Tribunal de Justicia de la Unión Europea responde la cuestión prejudicial presentada por el Tribunal Supremo en la causa penal del procés y establece una doctrina interpretativa del derecho europeo en el sentido de que la condición de diputado y la inmunidad asociada al cargo se producen desde el mismo momento de la proclamación oficial de los resultados electorales. Sin embargo, la sentencia no ha podido tener aplicación efectiva debido a la decisión del Tribunal Supremo de no suspender la causa principal y dictar sentencia antes de conocer la opinión del tribunal europeo, lo que pone en evidencia un mal uso del procedimiento prejudicial.

\section{PALABRAS CLAVE}

Eurodiputado, inmunidad, elecciones, prejudicialidad. 


\section{ABSTRACT}

The ruling of the Court of Justice of the European Union of December 19, 2020 (Oriol Junqueras case) is of special relevance because it determines when and how the status of member of the European Parliament and also the European parliamentary immunity are acquired. Until the ruling, there was no clear position on the matter, and the European court resolves it by prioritizing the exercise of the right to vote over other conditions eventually established by the law of the Member States. The judgment of the Court of Justice of the European Union answers the preliminary question submitted by the Supreme Court in the criminal case of the procés and establishes an interpretative doctrine of European law in the sense that the status of deputy and the immunity associated with the position occur from the moment of the official announcement of the electoral results. However, the judgment has not been able to be effectively applied due to the Supreme Court's decision not to suspend the main cause and to pass judgment before hearing the opinion of the European court, which highlights a misuse of the preliminary ruling procedure.

\section{KEYWORDS}

MEP, immunity, elections, prejudiciality.

\section{LABURPENA}

Europar Batasuneko Justizia Auzitegiaren 202oko abenduaren I9ko epaiak (Oriol Junqueras kasua) garrantzi berezia du, Europako Parlamentuko kide noiz eta nola izango den eta, era berean, Europako parlamentu-immunitatea noiz eta nola edukiko den zehazten duelako. Epaia eman arte, ez zegoen jarrera argirik horri buruz, eta Europako auzitegiak ebatzi zuen, botoa emateko eskubidea lehenetsiz estatu kideen zuzenbideak ezarritako beste baldintza batzuen gainetik. Europar Batasuneko Justizia Auzitegiaren epaiak Auzitegi Gorenak procés-aren auzi penalean aurkeztutako judizio aurreko arazoari erantzuten dio, eta Europako zuzenbidearen interpretazio-doktrina bat ezartzen du, hau da, diputatu-izaera eta karguari lotutako immunitatea hauteskunde-emaitzak ofizialki aldarrikatzen diren une beretik gertatzen direla. Hala ere, epaia ezin izan da benetan aplikatu, Auzitegi Gorenak auzi nagusia ez eteteko eta Europako auzitegiaren iritzia jakin aurretik epaia emateko hartutako erabakiaren ondorioz. Horrek agerian uzten du epaiketa aurreko prozedura gaizki erabili dela.

\section{GAKO-HITZAK}

Eurodiputatua, immunitatea, hauteskundeak, aurrejudizialtasuna.

\section{SUMARIO}

I. CONSIDERACIONES GENERALES.

II. LAS CIRCUNSTANCIAS DEL CASO.

III. EL MARCO NORMATIVO.

IV. LA RESPUESTA DEL TJUE.

V. LA INEFICACIA PRÁCTICA DE LA SENTENCIA DEL TJUE. 
I. CONSIDERACIONES GENERALES
La sentencia del Tribunal de Justicia de la Unión Europea de 19 de diciembre de 2019 (cuestión prejudicial C-502/19, caso Junqueras) tiene importancia política y jurídica porque clarifica aspectos esenciales de la inmunidad de los miembros del Parlamento Europeo, especialmente en lo que concierne al momento en que la prerrogativa de la inmunidad parlamentaria se origina y puede ser esgrimida por su titular frente al inicio o la continuación de una acción penal contra su persona.

Aunque la sentencia no entra explícitamente a valorar aspectos propios de la relación entre el ordenamiento europeo y el nacional, no hay duda alguna de que la doctrina que establece incide de lleno sobre esta siempre delicada cuestión. Así ocurre porque la opción interpretativa que adopta el tribunal devalúa claramente los efectos del derecho nacional en beneficio de la eficacia plena del derecho europeo.

La sentencia también tiene una importancia que va más allá del derecho sustantivo y se proyecta sobre la esfera procesal. Es así porque la cuestión prejudicial es un procedimiento indisociablemente unido a otro proceso judicial principal del cual deriva. La finalidad de la cuestión prejudicial es la necesidad de obtener una interpretación del derecho europeo cuando esta interpretación es necesaria para resolver el proceso principal o un aspecto relevante del mismo. Con la cuestión prejudicial se asegura que esta interpretación sea establecida por la justicia europea con carácter general y sirva como canon de aplicación del juez nacional. Es la lógica que se encuentra bajo los artículos 19.2.b) del Tratado de la Unión Europea (TUE) y 267.b) del Tratado de Funcionamiento de la Unión Europea (TFUE). La misma lógica que también lleva a la necesidad de suspender el procedimiento judicial nacional mientras el Tribunal de Justicia de la Unión Europea no se pronuncie.

Como es público y notorio, el Tribunal Supremo (TS) (Sala segunda, causa especial del procés núm. 20907/2017) planteó una cuestión prejudicial relacionada con la inmunidad parlamentaria de Oriol Junqueras mediante Auto de 1 de julio de 2019, como consecuencia de haber sido elegido eurodiputado en las elecciones celebradas el 26 de mayo del mismo año. Tras ver rechazado por el tribunal el permiso para comparecer ante la Junta Electoral Central (JEC) con el fin de prestar la promesa o el juramento de acatar la Constitución que exige el artículo 224.2 de la Ley Electoral General, el eurodiputado interpuso recurso de súplica ante el TS, siendo entonces cuando se planteó la cuestión prejudicial para obtener una interpretación del Tribunal de Justicia de la Unión Europea (TJUE) respecto a en qué momento se adquiere la condición de miembro del Parlamento Europeo y cuándo empieza a producir efectos la inmunidad asociada a este cargo.

Es, pues, con base en estos antecedentes como debe ser valorada la sentencia del TJUE y también la coherencia que respecto de ella puede establecerse sobre la actuación del TS una vez planteada la cuestión prejudicial. Una actuación que ya 
podemos adelantar calificándola de sorprendente y anómala puesto que ha llevado, en la práctica, a que la interpretación del TJUE sobre el momento en que la inmunidad europea produce efectos sea irrelevante y ha impedido, además, que el propio procedimiento prejudicial instado por el TS haya podido cumplir la finalidad para la que está concebido.

\section{LAS CIRCUNSTANCIAS} DEL CASO

Después de iniciada la fase de juicio oral en la causa penal del procés, Oriol Junqueras se presentó como candidato a las elecciones al Parlamento Europeo que se celebraron el día 26 de mayo de 2019. En el momento de presentarse como candidato, Oriol Junqueras se encontraba en situación de prisión provisional decretada por el TS desde el día 2 de noviembre de 2017. Sin embargo, esta situación no impidió la presentación de la candidatura por no ser causa de inelegibilidad ni incompatibilidad de acuerdo con la normativa electoral aplicable a las elecciones al Parlamento Europeo. El candidato resultó electo, y así se hizo constar en el acto de proclamación oficial de los resultados electorales al Parlamento Europeo (Acuerdo de la Junta Electoral Central (JEC) de 13 de junio de 2019, publicado en el BOE núm. 142, de 14 de junio de 2019).

El artículo 224 de la Ley Orgánica Electoral General (LOREG) establece que la JEC procede al recuento de votos emitidos en las elecciones al Parlamento Europeo, atribuye los escaños correspondientes a cada una de las candidaturas y proclama a los candidatos electos. Pero también establece que los candidatos proclamados electos deberán jurar o prometer acatamiento a la constitución ante la JEC en el plazo de cinco días desde su proclamación. Si este requisito no se cumple, la consecuencia prevista por la ley es la declaración de vacante del escaño correspondiente y la suspensión de todas las prerrogativas que pudieran corresponder al electo por razón del cargo, hasta que no se produzca el acatamiento a la Constitución. Como puede deducirse fácilmente de esta regulación, la LOREG no atribuye al acto de proclamación oficial de electos el valor determinante para la plena adquisición de la condición de miembro del Parlamento Europeo, puesto que para perfeccionar esta condición se exige el cumplimiento del requisito de acatar la Constitución.

Una vez proclamado electo, Oriol Junqueras solicitó al Tribunal Supremo un permiso extraordinario de salida del centro penitenciario para poder comparecer, bajo vigilancia policial, ante la JEC con el fin de cumplir con el requisito de acatamiento de la Constitución. Sin embargo, el permiso fue denegado y el diputado electo no pudo dar cumplimiento, contra su voluntad, al requisito establecido por la ley. Esta circunstancia determinó que la JEC excluyera al diputado electo de la comunicación oficial al Parlamento Europeo, declarando vacante el escaño correspondiente al interesado con suspensión de sus prerrogativas. 
La decisión del TS de denegar el permiso obliga a hacer dos consideraciones importantes. En primer lugar, resaltar la incoherencia que se produce entre la posibilidad legal de que una persona en situación de prisión provisional pueda presentarse como candidato a las elecciones al Parlamento Europeo y condicionar, al mismo tiempo, el resultado electoral a un requisito que obedece a una lógica interna o nacional y se antoja claramente desproporcionado cuando se trata del ejercicio de un derecho de sufragio activo y pasivo definido hoy en día como un derecho de ciudadanía europea. En segundo lugar, la enorme dificultad de comprender la motivación jurídica de la denegación de un permiso de salida que no podía poner en peligro la medida cautelar de prisión provisional; recordemos que el mismo candidato pudo asistir justo un mes antes y con permiso judicial a la sesión constitutiva del Congreso de los Diputados, después de haber sido elegido diputado en las elecciones celebradas el 28 de abril de 2019.

Resulta obvio que la denegación del permiso de salida para poder realizar el acto de acatamiento constitucional tuvo el efecto objetivo y práctico de impedir que el candidato electo pudiera perfeccionar su condición de eurodiputado y fue la causa determinante para que la JEC declarara la vacante del escaño y la suspensión de cualquier prerrogativa asociada al cargo de acuerdo con el artículo 224 de la LOREG. Esta es la consecuencia que se desprende del derecho español, aunque es imposible ocultar que se trata de una consecuencia ajena a la voluntad del interesado y deriva de una decisión judicial cuya motivación es muy difícil de justificar e incluso puede llegar a ser considerada como arbitraria.

Oriol Junqueras interpuso recurso de súplica contra la decisión del TS por la que se le denegó el permiso de salida para acudir ante la JEC, y es en el marco de este recurso cuando el TS decide plantear la cuestión prejudicial al TJUE, tal y como le pide el recurrente (Auto de 1 de julio de 2019). La lectura del auto pone en evidencia, sin embargo, una línea argumental que mezcla inapropiadamente consideraciones de orden penal asociadas al proceso penal (especialmente, la necesidad de asegurar la finalidad del proceso y el mantenimiento de la medida cautelar de prisión) con el debate propiamente dicho de las consecuencias asociadas al resultado del proceso electoral europeo (momento de la adquisición efectiva de la condición de miembro del Parlamento Europeo y reconocimiento de las prerrogativas asociadas al mismo). Como dice la misma sentencia del TJUE (apartado 35), se constata que el TS entiende que en este caso debería primar la medida de aseguramiento cautelar de Oriol Junqueras sobre las consecuencias inherentes al derecho de participación política en los trabajos del Parlamento Europeo, ya que en otro caso correría peligro la finalidad de la causa penal si se le autorizara a abandonar el territorio español (una consecuencia derivada de su condición de diputado y de la prerrogativa de la inmunidad europea).

Pero a pesar de ello, el TS no elude el debate acerca de la necesidad de plantear la cuestión prejudicial ante las dudas que pudieran existir, desde la perspectiva del derecho europeo, sobre el momento en que se debe considerar que se adquiere la condición de miembro del Parlamento Europeo y empiezan a surtir efectos los privilegios e in- 
munidades asociadas al cargo. En este contexto, el TS centra sus dudas interpretativas en dilucidar si la inmunidad parlamentaria se aplica sólo a los candidatos que han sido incluidos en la relación que la autoridad electoral competente de cada Estado ha traslado al Parlamento Europeo, una vez cumplidos los trámites exigidos por el derecho interno, y han tomado posesión de su escaño; y si las inmunidades parlamentarias son aplicables o no en el período temporal que precede a la primera sesión que el Parlamento Europeo celebra después de las elecciones.

Sin embargo, como adelantábamos antes, en la formulación de la cuestión prejudicial se encuentra demasiado presente el factor de "protección" de los intereses penales que contamina inevitablemente la propia iniciativa de plantear la cuestión prejudicial hasta el punto de poder llevar a la irrelevancia la decisión final del TJUE, al no asumirse plenamente las consecuencias que deberían derivar de la interposición de la cuestión prejudicial. Porque, inexplicablemente, esta interposición no lleva al TS a la decisión lógica y correcta de suspender el juicio oral y esperar a conocer el criterio del TJUE sobre las dudas interpretativas planteadas, como tampoco se resiste a plantear como cuestión prejudicial algo tan inapropiado como que el TJUE se pronuncie acerca de si es posible efectuar una ponderación (y determine quién deba hacerla y cómo) entre la protección que lleva aparejada la inmunidad parlamentaria y los derechos e intereses que se encuentran en juego en la causa penal.

Esta forma de proceder pone de relieve una lectura equívoca del procedimiento prejudicial europeo. Una lectura que parece buscar más una interpretación del derecho ad casum y que desconoce que el sentido último del procedimiento prejudicial no es otro que el de obtener un criterio interpretativo del derecho europeo para ser luego aplicado al proceso principal, sin más. Una lectura que también parece ignorar que el planteamiento de una cuestión prejudicial no pretende obtener una opinión teórica o consultiva del TJUE, sino un criterio decisorio y vinculante. Un efecto que es imposible respetar si el tribunal no suspende el proceso principal y espera a conocer el criterio del TJUE para actuar en consecuencia, máxime cuando la continuación del proceso puede llevar a que la decisión de la justicia europea devenga inoperante en la práctica. Como veremos más adelante, esto es precisamente lo que ha ocurrido en este caso al haber circunscrito el TS de manera inexplicable y artificiosa los efectos suspensivos de la prejudicialidad al recurso de súplica y no extenderlos a la causa penal en sí misma, a pesar de su inevitable incidencia sobre la misma.

\section{EL MARCO} NORMATIVO
Las elecciones al Parlamento Europeo y los privilegios e inmunidades de sus miembros carecen de una regulación unificada. Hasta el momento son ámbitos que no han pasado a ser competencia exclusiva europea, aunque existen cada vez más voces que plantean la conveniencia de que sea así. Pero el panorama normativo actual ofrece 
una situación mixta en la que conviven normas europeas y el derecho de los Estados. Como es lógico, esta situación favorece la existencia de problemas de integración e interpretación normativas, de los que no queda excluido el supuesto contemplado en la sentencia que comentamos.

En lo que concierne al derecho de la Unión, la normativa principal sobre las elecciones al Parlamento Europeo se encuentra en el artículo 14 del TUE y especialmente en el Acta relativa a la elección de los representantes en el Parlamento Europeo de 20 de septiembre de 1976, modificada en diversas ocasiones. Del artículo 14 del TUE es importante destacar la novedad que supuso cuando fue aprobado configurar el Parlamento Europeo como una institución que representa a los ciudadanos de la Unión mediante el ejercicio del derecho de sufragio, superando el anterior esquema que contemplaba a los eurodiputados como representantes de los Estados miembros. La consideración de los eurodiputados como representantes del conjunto de los ciudadanos de la Unión y no de los Estados permite establecer al TJUE la importante conclusión de que, conforme al principio de democracia representativa que se desprende del artículo 14 del TUE, es necesario que la composición del Parlamento Europeo refleje de forma fiel y completa la libre expresión de las preferencias manifestadas por los ciudadanos europeos por sufragio universal directo.

La naturaleza representativa basada sobre la ciudadanía europea queda perfectamente reafirmada en el artículo 39 de la Carta de los Derechos Fundamentales de la Unión Europea (CDFUE) cuando reconoce como derecho fundamental de todos los ciudadanos de la Unión el derecho de sufragio activo y pasivo en las elecciones al Parlamento Europeo. La conexión del proceso electoral europeo con un derecho fundamental, también europeo, está muy presente en la sentencia del TJUE y en su decantación, como veremos después con más detalle, a primar los efectos del ejercicio del derecho de sufragio (activo y pasivo) sobre eventuales requisitos establecidos por el derecho interno de los Estados que pudieran condicionar o anular aquellos efectos.

El Acta de 1976 sobre elección de los representantes al Parlamento Europeo debe interpretarse, como es lógico, a la luz de lo que se acaba de decir. El acta regula con carácter común y general diversos aspectos relacionados con el procedimiento electoral, pero al mismo tiempo hace una importante remisión a favor del derecho de los Estados en aspectos importantes. Concretamente, su artículo 8 establece que el procedimiento electoral se regirá, en cada Estado, por las disposiciones nacionales. Esta remisión permite que la LOREG regule el procedimiento electoral al Parlamento Europeo. Sin embargo, de esta remisión pueden originarse dudas interpretativas acerca de su alcance y, en especial, sobre cuándo termina el procedimiento electoral propiamente dicho. Esta cuestión es relevante en el caso que nos ocupa, pues no olvidemos que Oriol Junqueras no pudo perfeccionar su condición de eurodiputado, según las autoridades españolas, al no poder cumplir con el requisito de acatamiento de la Constitución al que se refiere el artículo 224 de la LOREG. 
¿La exigencia de este requisito posterior al acto de proclamación oficial de los resultados electorales forma parte del procedimiento electoral? El artículo 12 del acta de 1976 nos da una primera respuesta cuando dice que el Parlamento Europeo valida las credenciales de los eurodiputados tomando como referencia los resultados oficialmente proclamados por los Estados miembros. Esta norma permite interpretar que esta proclamación es la parte final o conclusiva del procedimiento electoral y hasta ella, y no más allá, alcanza la remisión al derecho interno. Curiosamente, la sentencia del TJUE no entra directamente sobre este espinoso problema, pero sí adopta un criterio claro y rotundo al respecto al no conceder al cumplimiento del requisito de acatamiento constitucional valor alguno para enervar los resultados electorales oficialmente proclamados. Este es un hecho determinante que desautoriza la posición adoptada por las autoridades españolas (TS y JEC) de negar a Oriol Junqueras su condición de miembro del Parlamento Europeo por no haber podido prestar promesa o juramento de acatar la Constitución.

De manera similar a la regulación electoral, la inmunidad de los miembros del Parlamento Europeo tampoco se rige íntegramente por el derecho europeo. El artículo 9 del Protocolo núm. 7 sobre los privilegios e inmunidades de la Unión Europea establece que mientras el Parlamento Europeo está en periodo de sesiones, sus miembros gozarán en su propio territorio nacional de las inmunidades reconocidas a los miembros del Parlamento de su país y en el territorio de cualquier otro Estado miembro de inmunidad frente a toda medida de detención y a toda actuación judicial.

La aplicación del protocolo ha planteado dudas sobre el periodo temporal que cubre la inmunidad cuando se refiere al periodo de sesiones. Existe una antigua jurisprudencia del TJUE (sentencias de 12 de mayo de 1964 y de 10 de julio de 1986) que interpreta dicha expresión en el sentido de que abarca todo el período en que el Parlamento celebra sesiones, incluyendo los espacios temporales entre sesiones. Sin embargo, esta jurisprudencia no da respuesta a qué ocurre respecto de la inmunidad en el período que abarca desde la proclamación de los resultados electorales hasta la primera sesión constitutiva del Parlamento Europeo. Esta importante cuestión no ha sido resuelta precisamente hasta la sentencia que aquí analizamos.

Otro problema que plantea la aplicación del protocolo europeo es cómo debe entenderse la remisión que hace al derecho nacional cuando se trata de determinar el alcance de la inmunidad de un eurodiputado cuando se encuentra en su país (el caso de Oriol Junqueras). La sentencia del TJUE no entra a fondo sobre esta cuestión, pero da a entender claramente que cuando el derecho nacional reconoce la inmunidad en el ámbito penal y condiciona su levantamiento a la tramitación de un suplicatorio ante la institución parlamentaria, esto se traduce también en el ámbito europeo en una garantía similar frente a cualquier acción penal que afecte a un eurodiputado. Conviene recordar a este respecto que el mismo Parlamento Europeo ha establecido una doctrina sobre las inmunidades parlamentarias con ocasión de la tramitación de los suplica- 
torios que se le han presentado. Esta doctrina entiende que la inmunidad se proyecta sobre hechos anteriores o posteriores a la elección del diputado y que es efectiva mientras dure su mandato si se trata de incoar tanto acciones judiciales como medidas de instrucción o de ejecución de sentencias, incluyendo los procedimientos de apelación y de casación (Informes de la Comisión de Reglamento y de Asuntos Jurídicos del Parlamento Europeo de 8 de octubre de 1990, 22 de abril de 1999, 10 de octubre de 2005, 2 de abril de 2009 y 2 de abril de 2019, entre otros). Según esta doctrina, el Parlamento Europeo entiende que la inmunidad cubre cualquier acción penal que se inicie contra uno de sus miembros o que ya esté en curso cuando es elegido, con excepción, como es lógico, de las situaciones judiciales que ya han quedado consolidadas en virtud de una sentencia firme.

De la doctrina del Parlamento Europeo que se expresa en la praxis seguida en la tramitación de los suplicatorios es importante destacar también que no concibe la inmunidad como una cláusula de irresponsabilidad, sino como una garantía de protección de la propia institución frente a actuaciones externas que pudieran menoscabar su composición y su funcionamiento. El Parlamento Europeo acoge así el concepto finalista de la inmunidad, que la concibe como garantía limitada frente a acciones penales atendiendo a las características que presenten los hechos imputados y a si existen o no indicios que permitan sospechar que tras el proceso penal se esconde la intención de perjudicar la actividad política del diputado.

Esta concepción de la inmunidad en el ámbito europeo deja en un segundo plano de interés la doctrina establecida por el Tribunal Supremo sobre los límites procesales de la inmunidad reconocida por el artículo 71.2 de la Constitución (Auto de 14 de mayo de 2019 recaído en la misma causa del procés). Esta doctrina establece que la inmunidad parlamentaria deja de producir efectos cuando en el momento de la elección una causa penal se encuentra ya en fase de juicio oral. Esta doctrina permitió al TS evitar la tramitación del suplicatorio cuando Oriol Junqueras fue elegido diputado al Congreso de los Diputados en las elecciones de 28 de abril de 2019. El TS podía haberse acogido a esta doctrina como argumento para justificar que no era necesario plantear una cuestión prejudicial teniendo en cuenta que el protocolo europeo remite al derecho interno en materia de inmunidades. Sin embargo, hay que deducir que el TS tenía sus dudas al respecto, ya que solo así se explica su decisión de plantear la cuestión prejudicial y el contenido de las preguntas que formula al TJUE. Por su parte, el TJUE es también conocedor de esta doctrina cuando se refiere a la misma en el apartado 21 de la sentencia, pero sin que este hecho llegue a condicionarle en su decisión. Puede deducirse, por tanto, que el estado procesal de la causa que sirvió en su día al TS como argumento para no reconocer la inmunidad de Oriol Junqueras como diputado nacional no ha tenido ninguna relevancia práctica cuando se ha tratado de su condición de eurodiputado. 
IV. LA RESPUESTA

DEL TJUE
La sentencia del TJUE de 19 de diciembre de 2019 resulta muy esclarecedora sobre cuándo se adquiere la condición de miembro del Parlamento Europeo y se goza, en este concepto, de la inmunidad que establece el artículo 9 del Protocolo sobre privilegios e inmunidades de la Unión.

La sentencia resuelve las dudas existentes sobre la situación que se produce en el ínterin que va desde el acto de proclamación oficial de los candidatos electos por las autoridades nacionales a la constitución del Parlamento Europeo y también sobre el valor que debe darse, en su caso, al cumplimiento de condiciones o requisitos que se proyectan más allá del proceso electoral y de su mismo resultado. Al mismo tiempo, el TJUE aprovecha la sentencia para dejar claro cuáles son los efectos de la inmunidad europea y cómo deben actuar ante la misma las autoridades nacionales.

El TJUE parte de la base de que el funcionamiento de la Unión Europea y, en especial, del Parlamento Europeo, se fundamenta en el principio de la democracia representativa (arts. 2 y 10 del TUE) y que, aplicando este principio, el artículo 14.3 del TUE prevé que los miembros del Parlamento Europeo son elegidos por sufragio universal directo, libre y secreto, siendo este acto de elección el principal atributo y fundamento de la condición de eurodiputado. Esta premisa lleva al TJUE a afirmar de manera clara e inequívoca que una persona que ha sido oficialmente proclamada electa al Parlamento Europeo adquiere por este hecho y desde ese momento la condición de miembro de dicha institución, a los efectos del artículo 9 del Protocolo sobre privilegios e inmunidades de la Unión y goza, en este concepto, de la inmunidad prevista por ese precepto (apartado 81 de la sentencia).

Como puede deducirse fácilmente, para el TJUE el hecho determinante de la adquisición de la condición de miembro del Parlamento Europeo es el acto de proclamación oficial de los resultados electorales. El principio de democracia representativa impone este efecto y obliga, por consiguiente, a que la composición del Parlamento Europeo refleje de forma fiel y completa la libre expresión de las preferencias manifestadas por los ciudadanos de la Unión y a que el Parlamento quede asimismo protegido en el ejercicio de sus funciones asegurando que cada uno de sus miembros, tras la proclamación oficial de los resultados electorales, tenga la posibilidad de dirigirse sin impedimentos a las sesiones parlamentarias y ejercer así su cargo (apartados 83, 84 y 85 de la sentencia). Por esta razón, el TJUE entiende que la inmunidad debe desplegar sus efectos desde el mismo momento de la proclamación oficial de los resultados electorales al ser el instrumento que garantiza en primera instancia al Parlamento Europeo una protección completa y efectiva de su composición, funcionamiento e independencia, y asegura al mismo tiempo la eficacia del derecho de sufragio pasivo que reconoce el artículo 39. 2 de la CDFUE (apartados 82 y 86 de la sentencia).

Como decíamos antes, los artículos 14. 3 del TUE y 39.2 de la CDFUE constituyen los referentes básicos que inspiran la decisión del TJUE y le llevan a ser extraordinariamente explícito sobre cuáles son las consecuencias que se deducen de ellos. El princi- 
pio democrático y su fundamento último en el derecho de sufragio activo y pasivo de los ciudadanos europeos lleva al TJUE a conceder al acto de proclamación oficial de los resultados electorales un valor absoluto que no puede verse anulado por la eventual existencia de otros condicionantes establecidos por los Estados miembros, como es el requisito de acatamiento constitucional establecido por el artículo 224.2 de la LOREG. Sin entrar a valorar directamente este precepto, la sentencia del TJUE lo condena a la inoperancia al quitarle cualquier relevancia y efecto respecto de la adquisición de la condición de miembro del Parlamento Europeo y la atribución de la prerrogativa de la inmunidad en los términos que acabamos de ver.

La principal consecuencia que de todo ello extrae el TJUE es contundente y se expresa con meridiana claridad en el apartado 87 de la sentencia y en el apartado primero de su parte declarativa. Esta consecuencia es que goza de inmunidad una persona que, como Oriol Junqueras, fue oficialmente proclamada electa al Parlamento Europeo cuando se encontraba en situación de prisión provisional en un proceso penal por delitos graves, aunque no haya sido autorizada a cumplir ciertos requisitos previstos en el derecho interno tras la proclamación ni a desplazarse al Parlamento Europeo para participar en su primera sesión.

Por otra parte, la sentencia del TJUE también es muy clara sobre las consecuencias que implica la inmunidad reconocida en estos términos. El TJUE responde al TS que la inmunidad directamente asociada a la proclamación oficial de los resultados electorales significa que, si el tribunal nacional estima que debe mantenerse la medida de prisión provisional, debe solicitar a la mayor brevedad al Parlamento Europeo que suspenda la inmunidad y cursar el correspondiente suplicatorio, puesto que la inmunidad implica el levantamiento de la medida de prisión impuesta a la persona que la tiene reconocida al objeto de poder ejercer sus funciones parlamentarias (apartados 91 y 92 de la sentencia y apartado segundo de su parte declarativa).

V. LA INEFICACIA PRÁCTICA DE LA SENTENCIA DEL TJUE
Como es público y notorio, existe una diferencia radical entre lo que se desprende de la sentencia del TJUE y lo que realmente ha sucedido. Puede afirmarse, sin exagerar, que la doctrina establecida por el TJUE no ha sido útil ni ha servido en la práctica al objetivo que debe procurar cualquier cuestión prejudicial. Esto se debe a una mala praxis del TS, que ha ignorado cuál es esta función y cómo ésta debería haber incidido sobre el proceso principal. Como hemos dicho antes, el TS decidió no suspender la causa del procés acotando el problema a un incidente procesal (el recurso de súplica contra la denegación del permiso para acudir ante la JEC). Sin embargo, es obvio que la cuestión prejudicial, por la índole de las preguntas formuladas al TJUE, incidía de lleno sobre el procedimiento principal, puesto que la respuesta del TJUE podía afectarlo cuando aún se estaba desarrollando. 
El propio TJUE es consciente de esta anomalía cuando en el apartado 58 de la sentencia asume que la interpretación del derecho europeo que solicita el TS guarda relación directa con el objeto del litigio principal y que el problema suscitado en dicho litigio no es hipotético, sino real. Y también lo fue el abogado general en sus conclusiones (presentadas el 12 de noviembre de 2019) cuando alertó del problema que significa la no suspensión de la causa principal tras la presentación de la cuestión prejudicial ante el TJUE y haberse dictado sentencia antes de obtener la respuesta (sentencia del TS de 14 de octubre de 2019). Habida cuenta de que la sentencia del TS conlleva la anulación del mandato representativo de Oriol Junqueras (inhabilitación firme), el abogado general se pregunta en sus conclusiones si tiene sentido alguno continuar la cuestión prejudicial cuando el interesado ha sido juzgado y condenado sin que el Parlamento Europeo haya tenido la oportunidad de pronunciarse sobre la suspensión de su inmunidad o sobre el eventual mantenimiento de la misma (apartados 100-102 del escrito de conclusiones).

De todo ello se desprende no solo un mal uso de la cuestión prejudicial por parte del TS, sino algo más grave aún, como es haber ignorado los efectos de la inmunidad parlamentaria en el momento que esta ya actuaba según el TJUE; esto es, desde el día 13 de junio de 2019, fecha en que la JEC procedió a la proclamación oficial de los resultados electorales e incluyó en ella a Oriol Junqueras. La continuación del juicio del procés y la posterior sentencia del TS son, una vez conocida la doctrina del TJUE, actos irreconciliables con la inmunidad parlamentaria europea y sus efectos de garantía a nivel institucional y personal. A otro nivel, el comportamiento del TS también lo deja en evidencia al haber asumido el riesgo de que la cuestión prejudicial impulsada por él mismo pudiera perder la utilidad que siempre debe tener un procedimiento de estas características.

El TJUE ha sido plenamente consciente de este problema y hay que agradecerle que, pese a ello, no renunciase a responder y devolver la pelota al TS al afirmar que la cuestión prejudicial no había perdido necesariamente vigencia tras la sentencia del TS de 14 de octubre de 2019 y considerar que es al tribunal remitente a quien incumbe precisar los efectos relacionados con la inmunidad de Oriol Junqueras "con observancia del derecho de la Unión y en particular del principio de cooperación leal" (apartado 58 de la sentencia). La invitación quedaba hecha, pero es obvio que el margen de maniobra era muy exiguo y complejo una vez dictada la sentencia del procés. Parece que el propio TS no se ha querido dar por aludido, y su respuesta se expresa en el Auto de 9 de enero de 2020. Una resolución que no hace ningún esfuerzo, ante los hechos consumados, para corregir los propios errores del tribunal y aplicar los efectos que derivan de la doctrina establecida por el TJUE.

El lector podrá sacar las conclusiones oportunas de todo lo expuesto. En cualquier caso, quien suscribe este comentario prefiere limitarse a poner de relieve el contraste de lo fundamentado de la interpretación del derecho europeo que realiza el TJUE frente a la extravagante y anómala gestión del procedimiento prejudicial por parte del TS, que ignora las consecuencias de esa interpretación. Una interpretación en la que, además, están en juego valores y derechos europeos fundamentales. ^ 